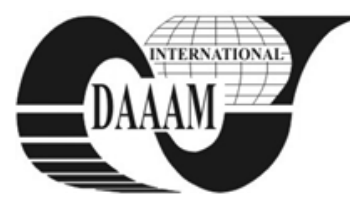

Annals of DAAAM for 2011 \& Proceedings of the 22nd International DAAAM Symposium, Volume 22, No. 1, ISSN 1726-9679 ISBN 978-3-901509-83-4, Editor B. Katalinic, Published by DAAAM International, Vienna, Austria, EU, 2011 Make Harmony between Technology and Nature, and Your Mind will Fly Free as a Bird Annals \& Proceedings of DAAAM International 2011

\title{
STUDY OF THE EVOLUTION OF ATMOSPHERIC PRECIPITATION IN MOLDAVIA REGION (ROMANIA) OVER THE LAST 65 YEARS
}

\author{
MACHIDON, O[vidiu] \& MACHIDON, D[ana]
}

\begin{abstract}
This paper presents the time evolution and trends in the amounts of atmospheric precipitation and the number of days with a precipitation of $>20 \mathrm{~mm}$ and $30.0 \mathrm{~mm}$, in Moldavia region (Romania), in the period of 1945 to 2010. The data, uninterruptedly measured by the seven weather stations within the 65-year period, are summarized in tables, and their interpretation is supported by graphics. The study concludes that the annual rainfall amounts and their torrential nature have been continuously increasing over the last 65 years.
\end{abstract}

Key words: atmospheric precipitation, torrential rain, trends

\section{INTRODUCTION}

In the first decade of the 21 st century, Moldavia faced an unprecedented sequence of hot periods and very moist and rainy periods. Some of which surpassed the relevant meteorological observation.

This is the first study ever to be conducted on the evolution of atmospheric precipitations over a 65 -year period in Moldavia (Romania). Most of the recent studies, which analyzed the surplus rainfall and/or its variation and the climate change in Romania, showed the evolution of atmospheric precipitations in the period of 1961 to 2000 (Dragota, 2006) and of 1961 to 2007 respectively (Busuioc et al., 2010). Other recent studies analyzed the extreme weather events of the last 10 years in Moldavia region as well as their impact on the natural or anthropogenic environment (Machidon \& Budui, 2009, Apostol \& Machidon, 2009). NMA of Romania have recently conducted an assessment of the current climate in Romania, featuring the atmospheric precipitation, mainly in terms of its territorial distribution and less over time evolution (Climate of Romania, 2008).

Moldavia region is a territory in Northeastern Romania with an area of $35.806 \mathrm{~km}^{2}$. To highlight the differences between the periodic evolution of precipitation average values and the time evolution of the days with precipitation amounts of $>20 \mathrm{~mm}$ and $30 \mathrm{~mm}$, data from the 1945-2010 period, being the most consistent, have been used, However, due consideration was given to the fact that meteorological stations are located in the most different geographical and physical conditions (Fig 1).

This paper is primarily based on factual material represented by data continually measured throughout the 1945-2010 period by the Moldavian weather stations in Botoşani, Suceava, Iaşi, Piatra Neamt, Bacău, Birlad and Galati. The data is summarized in tables and their interpretation is supported by graphs. The statisticalmathematical processing of the climatic data and their graphical representation are the methods through which the corpus of data collected from the weather stations measurements has been developed. Furthermore, both methods were used in the graphical transposition of the results obtained by averaging the data from the six weather stations. In order to establish a trend, we have used the method of moving averages, on a time series of 10 years, shifted with a year calculated by averaging the values recorded by those weather stations. The trend line has been drawn by using EXCEL.

We look forward to continuing the research on the temporal and special evolution of the meteorological phenomena of risk, such as hail, storms, extreme temperatures, droughts, etc., in the current context of the climate change in Moldavia (Romania). The research results are highly significant, not only for agriculture, but also for economy, overall investment sector and human life in general.

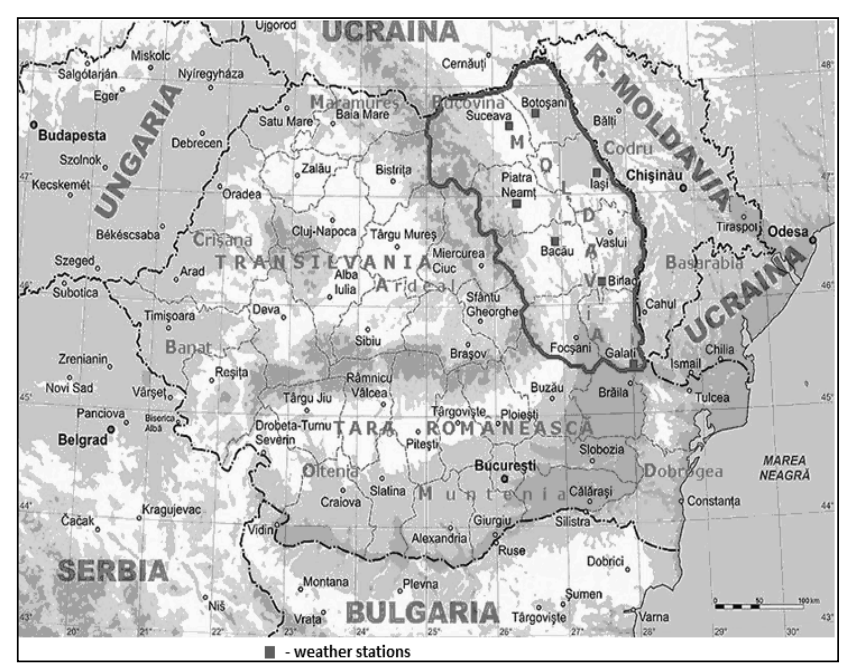

Fig. 1. Locations of weather stations in Moldavia region (Romania)

\section{RESULTS}

In table 1, One can readily observe that, the periodic evolution of precipitation average values, throughout 22-year intervals in the 1945 to 2010 period, indicates a rising trend analyzed by 5 of the 7 weather stations.

\begin{tabular}{|c|c|c|c|}
\hline $\begin{array}{c}\text { Period } \\
\text { Stations }\end{array}$ & $\mathbf{1 9 4 5 - 1 9 6 6}$ & $\mathbf{1 9 6 7 - 1 9 8 8}$ & $\mathbf{1 9 8 9 - 2 0 1 0}$ \\
\hline Botosani & 515.9 & 559.5 & 593.4 \\
\hline Suceava & 585.3 & 628.0 & 628.8 \\
\hline Iasi & 500.6 & 605.8 & 562.3 \\
\hline Piatra Neamt & 620.8 & 622.4 & 629.0 \\
\hline Bacau & 520.6 & 555.8 & 606.7 \\
\hline Birlad & 466.7 & 522.8 & 490.4 \\
\hline Galati & 425.6 & 492.5 & 497.4 \\
\hline Average & $\mathbf{5 1 9 . 4}$ & $\mathbf{5 6 9 . 5}$ & $\mathbf{5 7 2 . 6}$ \\
\hline
\end{tabular}

Tab. 1. The periodical average amount $(\mathrm{mm})$ of the atmospheric precipitation recorded by the weather stations

Long-term trends, in 1945-2010 period (Fig. 2), of the evolution in the atmospheric precipitation amounts, show the same rising trend in Moldavia region as well. 


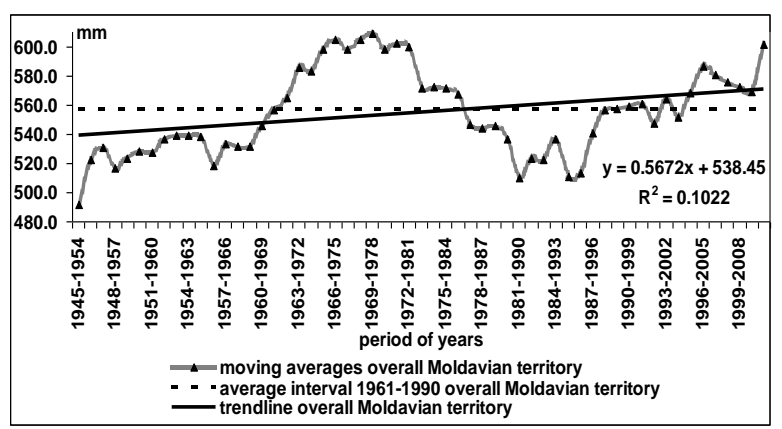

Fig. 2. The moving averages over a 10-year time series, shifted successively with one year of the average precipitation amounts overall Moldavian territory

Long-term trends (1945 - 2010) of the weights of seasonal precipitation within the annual values reveal that, during the cold semester, the weight has a slightly decreasing trend, while in the warm semester, the weight of precipitation amounts within annual values shows a slightly increasing trend (Fig. 3).

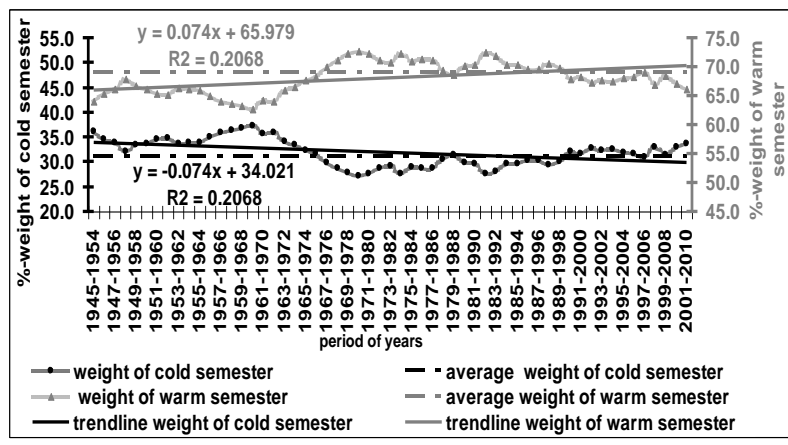

Fig. 3. The moving averages over a 10-year time series, shifted successively with one year, of the evolution of the weight $(\%)$ of the half-yearly precipitation amounts within the annual values overall the Moldavian territory

As in the case of long-term evolution trend ( 1945-2010) of the atmospheric precipitation (Fig. 2), one can observe that the number of days with a precipitation of $>0.1 \mathrm{~mm}$ (Fig. 4) shows an increasing trend overall the Moldavian territory.

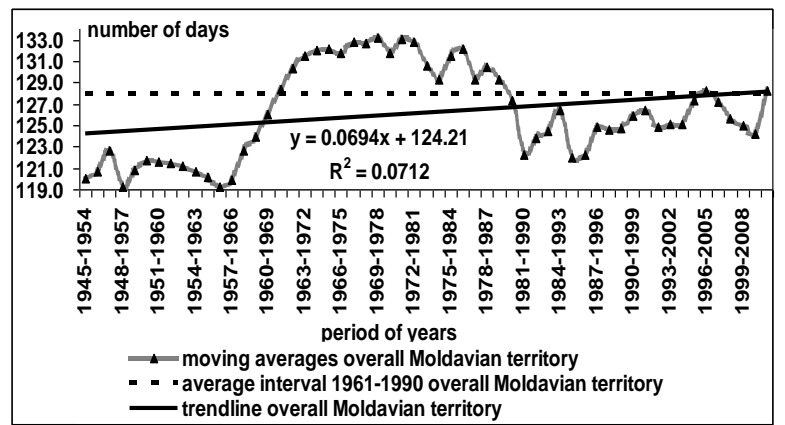

Fig. 4. The moving averages on a 10-year time series shifted successively with one year of the number of days with a precipitation of $>0.1 \mathrm{~mm}$ overall Moldavia territory

The trends of the weights of the annual number of days with a precipitation of $>20 \mathrm{~mm}$ and $30.0 \mathrm{~mm}$, the annual number of days with a precipitation of $>0.1 \mathrm{~mm}$ (Fig. 5) and the actual annual number days with a precipitation of $>20$ $\mathrm{mm}$ and $30.0 \mathrm{~mm}$ (Fig. 6) indicate an increasing movement of the values.

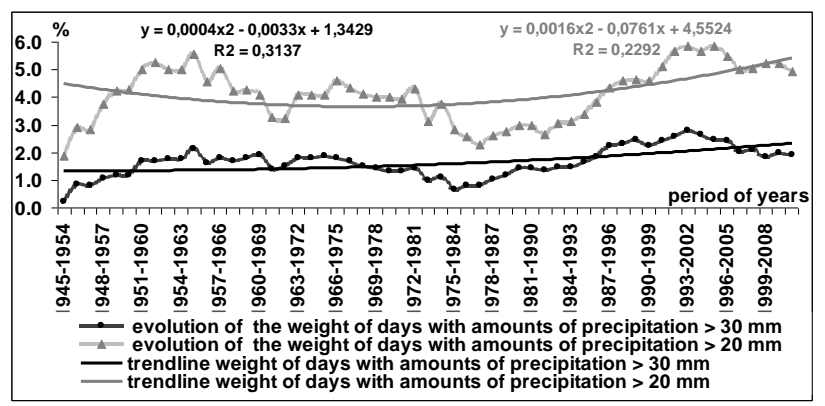

Fig. 5. The moving averages on a 10-year time series, shifted successively with one year, of the evolution of the weight of days with precipitation amounts of $>20 \mathrm{~mm}$ and $30.0 \mathrm{~mm}$ as opposed to the number of days per year with precipitation amounts of $>$ 0,1 $\mathrm{mm}$ overall Moldavia territory (1945-2010)

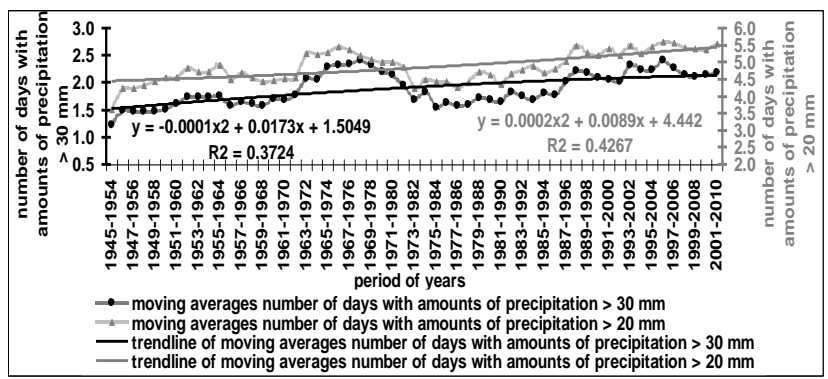

Fig. 6. The moving averages on a 10-year, shifted successively with one year, of the number of days with precipitation amounts of > 20, $30 \mathrm{~mm}$, overall Moldavia territory (1945-2010)

\section{CONCLUSIONS}

Calculations based on long sets of observations (1945 - 2010) have indicated that the annual quantities of precipitation overall the Moldavian territory show an increasing trend. The average annual number of days with a precipitation of $>30 \mathrm{~mm}$ indicates a shift of the deviations towards the register of values above average, which is argument case in point for the increasing torrential nature of precipitation over the last 65 years in Moldavia.

\section{ACKNOWLEDGMENTS}

O. Machidon is supported by a POSDRU grant no. 89/1.5/S/49944 "Developing the innovation capacity and improving the impact of research through post-doctoral programs", Alexandru Ioan Cuza University, Iasi.

\section{REFERENCES}

Apostol, L \& Machidon, M. (2009). Impact of the abundant precipitation of $22-27$ July 2008 in the north and north-east Moldavia, Present Environment and Sustainable Development, vol. III, Ed. Alexandru Ioan Cuza University, pp 73-82, ISSN 1843-5971, Iaşi

Busuioc, A.; Caian, M.; Cheval, S.; Bojariu, R.; Boroneant, C.; Baciu, M. \& Dumitrescu, A. (2010). Variability and climate change in Romania, Ed. Pro Universitaria, ISBN 978-973129-549-7, Bucharest

Dragota, C. (2006). Excess rainfall in Romania, Ed. Academiei Romane, ISBN 973-27-1435-2, Bucharest

Machidon, O \& Budui, V. (2009). Meteorological features of the 2006-2007 agricultural year in the basin Bârlad, Stefan cel Mare University Annals, s. Geografie, t. XVIII, 81-92, ISSN 1583-1469, Suceava

NMA, Romania. (2008). Climate of Romania, Ed. Academiei Romane, ISBN 978-973-27-1674-8, Bucharest

*** (1945-2010), Meteorological Tables TM1-1M, N.M.A, Bucharest 